\title{
Improving Prevention Compliance through Appropriate Incentives: Theoretical Modelling and Empirical Evidence $^{\mathrm{a}}$
}

\author{
Udo SCHNEIDER $^{\mathrm{b}}$ and Jürgen $Z_{\text {ERTH }}^{\mathrm{c}}$
}

JEL-Classification: I12, D82, C23.

Keywords: incentives in prevention; information distribution; hazard model.

\section{Introduction and Motivation}

As the patient's role in the health production process as a productive input factor is increasingly gaining recognition, prevention has become a dominant role in many health care systems. However, prevention is often discussed in the sense of its cost-saving impact, which cannot be proved definitely, and there is less discussion on insurers' based incentives for encouraging prevention. ${ }^{1}$ In the case of smoking, for example, most papers ascertain the medical as well as the economic burden of smoking that could be reduced by some smoke-cessation measures and forms of anti-smoking policies. ${ }^{2}$

Referring to recent literature on smoking prevention, the negative impact of smoking on individual health is unambiguous. Moreover, many studies also elaborate the rising health care costs of smoking. For Germany, WeLte et al. (2000) estimate the direct and indirect costs of smoking, including respiratory diseases and cancer, at about $€ 28.6$ to 43.5 billion in 1993. In a recent study, Neubauer et al. (2006) approximate the total costs of smoking in 2003 at about $€ 21$ billion

a For helpful comments we would like to thank Stefan Napel, Stefan Felder, Andrew Jones, Nigel Rice, Andreas Schmid and two anonymous referees. The remaining errors are entirely ours.

b Udo Schneider, University of Bayreuth, Chair of Public Finance, D-95440 Bayreuth, udo. schneider@uni-bayreuth.de.

c Jürgen Zerth, International Dialog College and Research Institute (Diakonie Neuendettelsau), D-91564 Neuendettelsau, juergen.zerth@diakonieneuendettelsau.de.

1 Cf. Cohen et al. (2008) for a short view on the scope of prevention policies.

2 See Rice et al. (1984) and also Volpp et al. (2009). Welte et al. (2000) elaborate the costs of smoking from a German point of view. 
in Germany. Among these costs, $€ 8.8$ billion are related to work loss days and early retirement. According to STURM (2002), smoking at present or having ever smoked is associated with increasing costs in the United States. Sturm estimates an average increase of $\$ 230$ for inpatient and ambulatory care, resulting in a 21 percent increase in health care costs and 23 to 30 percent in medication costs.

Up to now, these results have not been transformed into appropriate incentive structures in insurance-based health care systems. Our contribution is to discuss the impact of insurance-based incentives for doing prevention and to compare these theoretical results with an empirical analysis of the decision to quit smoking.

We employ the standard model in literature of EHRLICH and BECKer (1972) and expand this model with the idea of an information environment the insurer faces, i.e. he sets his contract parameter policies contingent on the information environment he perceives. Moreover, we distinguish between two types of health care models. In the basic model, the insurer can charge risk-orientated premiums. We compare this setting with a model where only income-related contributions are possible. Furthermore, we analyse the prevention decision using German Data on smoking for discussing the impact of insurance parameters and the relevance of complementary factors. However, we have to consider that there exists less contractual liberty in health care coverage in Germany. The paper ends with a conclusion.

\section{Recent Research}

Referring to the literature of primary prevention, two strands of literature can be found (cf. Kenkel, 2000; Haynes, 1978 or Haynes et al., 2002). One deals with forms of rational addiction in the sense of Becker and Murphy (1988). The other one discusses aspects of prevention strategies in the context of health care measures that are offered by health care institutions like state authorities or insurers. The obvious inconsistency of prevention efforts has been noted in several surveys focussing on secondary prevention activities (e.g. GIVEON and KaHAN, 2000). When considering typical behavioural risks like drinking, smoking or mal-nutrition, the aspect of patients' influence is obvious.

Theoretical literature about prevention in insurance-based models is still underrepresented. Miceli and Hefretey (2002) analyse in how far alternative health care financing plans affect the choice of preventive care by risk-neutral consumers and providers' choice of capacity, but they do not model an insurer explicitly. Miceli and Heffley find that pure fee-for-service plans lead to a Pareto-optimal 
choice of both preventive care and capacity. The same result applies to a mixed plan, which includes a lump-sum fee and a kind of cost sharing between health care provider and cost-payer.

In contrast to this, a pure prepaid plan may lead to under- or over-consumption of prevention. In addition, BARIGOZZI (2004) shows to which extent investments in secondary prevention can be viewed as self-insurance activities by analysing the influence of reimbursement schemes on prevention and treatment. Her main finding is that the optimal reimbursement scheme encourages treatment and prevention. Moreover, it is required that prevention reduces the cost of treatment. Ellis and MANNING (2007) examine optimal health insurance, differentiating between both prevention and treatment separately. They show that in the case where individuals ignore the impact of their preventive activities on the premium at least some coverage for preventive care is desirable. Recent papers shed light on the interaction between prevention and non-prevention behaviour. PoutvaARA and Siemers (2008) stress the impacts of different smoking regulations on welfare and institutional consequences by using different bans. Referring to the consequences of the literature on smoking bans (e.g. Dunhan and Marlow, 2000) we can also argue that the prevention environment plays a decisive role in fostering appropriate prevention strategies.

To sum up, there remains the question how monetary and non-monetary incentives set by an insurer can enforce patient's prevention effort when the contract parameters are bound to different levels of information the insurer can perceive.

Whereas the literature discussed above mainly stresses the relationship between a health care provider and patients that are enrolled in different health care plans competing with each other, we use German data where health care supply has been mainly organised by a collective agreement. From the patient's point of view, the opportunity costs of doing prevention or being compliant seem to be relevant. Hence, the patient has to consider the form of premium setting and the additional costs of doing no prevention at all. It seems plausible that the preventive activities depend on the level of insurance as well as on the distribution of information between the insurer and the insurant. This raises the question of how to deal with this ex ante moral hazard in providing the optimal amount of prevention. It is interesting to explore the connection between cost sharing and the impact of intangible costs in consequence of doing prevention. The insurer has an additional interest to establish a complementary prevention environment in order to strengthen monetary incentive schemes.

For the sake of simplification, we concentrate our theoretical and empirical interest on the patient's decision to smoke and to quit smoking. As smoking is 
related to high medical risks and can be discussed as a form of direct individual responsibility, this kind of individual behaviour is very suitable for theoretical as well as empirical investigation. ${ }^{3}$ Hence, we are interested in the potential impacts of insurance on the individual's decision to reduce or to quit smoking.

\section{Theoretical Model}

Our model refers to a principal-agent setting in which the patient is acting as an agent in deciding about his preventive effort after the contract parameters have been set. Basically, the patient can purchase insurance for which he has to pay a premium $\pi$ which will be charged as a risk-orientated premium in the basic model. In an expanded form of the model, we introduce income related contributions that resemble the kind of health insurance, which is typical for "Bismarck-Systems" like Germany. For the patient's Von Neumann-Morgenstern utility function $U$ it is assumed that the patient owns an initial wealth $W$ and is risk averse in disposable income ( $U$ is concave). The probability of getting sick is $p$, with $p \in[0,1]$.

In the case of illness, the patient suffers a health shock in monetary units $L$. The patient can obtain medical treatment $x \leq L$ that helps to compensate the exogenous medical health shock $L$. Moreover, in the case of treatment, he faces some cost sharing which can lessen the financial compensation for the health shock $L$. Cost-sharing $x \leq L$ encompasses a monetary co-payment as well as a reduction in the coverage level. If $x=x^{\max }$ the maximum level of $x$ with no costsharing is $K$. We do not explicitly differentiate between monetary co-payments and reduction in coverage, because both forms of cost sharing raise the costs for the medical supply the patient has to pay individually.

To avoid an illness, the patient engages in primary prevention activities ${ }^{4} e$ that lowers the probability of getting sick $p(e)$. These activities are set after the

3 For the discussion of the economic impact of smoking and the potential cost savings due to smoking cessation ideas, see ChaloupKa and WARnER (1999). As an example of insurer interests in smoking prevention, SCHAUfFLER and PARKInson (1993) analyse the coverage for smoking cessation services in the US.

4 For the sake of simplification, we do not differentiate between primary prevention and prevention in general. Additionally we discuss a continuous form of the variable $e$ that stands for the prevention activities. In reality, prevention activities often occur in a discrete way, i. e. the decision for doing sport or not, or the decision for smoking or quitting smoking is discrete. Hence, we incorporate the ex ante decision for doing primary prevention as well as the intensity level in the variable $e$. 
insurance contract has been established. Here, the relation between the probability of an illness and prevention is convex:

$$
\frac{\partial p(e)}{\partial e}<0 ; \frac{\partial^{2} p(e)}{\partial e^{2}}>0
$$

The patient's prevention $e$ is associated with disutility $C(e)$ which is a convex function of the prevention effort $e$ and depicts the patient's opportunity costs. The expected utility function is additive-separable in income and disutility: ${ }^{6}$

$$
E U=p(e) \cdot U[W-\pi-L+K]+(1-p(e)) \cdot U[W-\pi]-C(e)
$$

In the subsequent analysis, the following notation is used as a simplification to express the patient's utility:

$$
\begin{aligned}
U_{S} & =U[W-\pi-L+K] \\
U_{H} & =U[W-\pi]
\end{aligned}
$$

If the patient is sick, his income-related utility is $U_{S}$, whereas in a healthy condition he only has to pay the insurance premium and his utility is denoted $U_{H}$, with $U_{S}<U_{H}$.

The insurance company is risk neutral and finances the health care expenditures in the case of an illness $(p)$ for a premium $\pi$. The insurance pays for all the treatment costs in the first-best case and supplies this service at actuarial fair premiums on a competitive insurance market:

$$
\pi=p(e) \cdot K
$$

Possessing full information the insurer is able to write contracts contingent on $e$ and to decide about the necessary medical services for treating the illness and the contract parameters $\pi$ and $K$. As proposed in Stewart (1994) the

5 This idea is very similar to the attempt used by Miceli and Heffley (2002). It is very important to distinguish between the basic probability of falling ill and the effort-dependent probability for a better and a worse level of given illness. Especially when considering forms of chronic illnesses the patient has to live with the consequences. Therefore, other aspects may influence the probability of getting ill.

6 An additive-separable utility function states that the degree of risk-aversion of the incomedependent utility $(U()$.$) does not vary with the prevention-level (e) (cf. Macho-STADler and$ Pérez-Castrillo, 2001, p. 19). 
insurance company maximises the patient's expected utility subject to its zero profit condition:

$$
\begin{gathered}
\max _{e, \pi, K} E U=p(e) \cdot U[W-\pi-L+K]+(1-p(e)) \cdot U[W-\pi]-C(e) \\
\text { s.t. } \pi=p(e) \cdot K
\end{gathered}
$$

Inserting the zero-profit condition into the objective function, we can directly infer the optimal level of medical services and preventive activities:

$$
\begin{aligned}
\max _{e, K} E U & =p(e) \cdot U[W-p(e) \cdot K-L+K] \\
& +(1-p(e)) \cdot U[W-p(e) \cdot K]-C(e)
\end{aligned}
$$

The first-order condition for the preventive activity after rearranging is:

$$
\frac{\partial E U}{\partial e} \Rightarrow p^{\prime}(e) \cdot\left(U_{S}-U_{H}\right)-p^{\prime}(e) \cdot K\left[p(e) U_{S}^{\prime}+(1-p(e)) U_{H}^{\prime}\right]=C^{\prime}(e) .
$$

Looking at the optimum level, the insurance company chooses the level of prevention $e^{*}$, where marginal benefits equal marginal costs. Here, the marginal costs of prevention (or marginal effort) on the right-hand side rise with an increase in $e$. On the left-hand side, the first term is the direct gain in utility from a decrease of the probability of falling ill. The second term is the indirect effect of a higher prevention level due to the declining insurance premium of the patient.

Partial derivation of equation (4) with respect to medical services $K\left(K \equiv x^{\max }\right)$ leads to the typical result:

$$
\frac{\partial E U}{\partial K} \Rightarrow \frac{U_{H}^{\prime}}{U_{S}^{\prime}}=1
$$

In the first-best case, the optimal coverage only depends on the probability of falling ill. Moreover, equation (6) implies that in the first-best case there is no need for any additional cost-sharing strategy. 


\subsection{Asymmetric Information: The Patient's Sight}

In the case of asymmetric information, it is no longer possible for the insurance company to contract upon the optimal level of prevention. In our approach, two restrictions are important: First, we only discuss the prevention decision made after a contract has been established and, second, we refrain from aspects of the insurer's self-interest in risk selection.

We include a form of monitoring that completes normal incentive constraint used in moral hazard approaches. ${ }^{7}$ However, we do not focus on different forms of contracts set by the uninformed side to detect different types of patients. Similar to a traditional screening model, we assume that the uninformed agent is playing first.

Like in typical moral hazard models (cf. Zweifel and Manning, 2000 or more general in Macho-Stadler and Pérez-Castrillo, 2001), one problem for the insurer is the assessment of the patient's prevention activities. Therefore, our model has to consider two separable problems with the patient's moral hazard regarding prevention. The first one is the result of a typical form of lack in the patient's control because, opposite to the first-best case, the insurer and the patient do not simultaneously maximise their utility function. The second problem is related to disturbance in information perception, which is relevant for the insurer as well as the patient. In other words, neither the patient nor the insurer can really interpret the direct impact of additional prevention activity on the patient's health.

The patient can try to give better information by some kind of signalling. For depicting that influence, we introduce a signal $\lambda$ that encompasses the prevention efforts $e$ as well as screening strategies $m .{ }^{8}$ This means that the information signal $\lambda$ itself depends on the effort level $(e)$ and could be enhanced by additional monitoring activities $(m)$ by the insurer.

Our assumption is that more prevention efforts as well as more monitoring activities strengthen the information transmission from the insured to the

7 Considering the findings of Shavell (1979), approaches of ex post detection in form of monitoring could be cheaper than alternative ex ante signalling and screening activities. MasColell et al. (1995) show different aspects of signalling and screening in order to reveal the type of an agent.

8 The information disturbance $\lambda$ is deliberately integrated in the patient's utility function to show the impact of different risk aversion scenarios on the expected valuation. Recent research concerning risk preferences contingent to deductible choice within car insurance shows a higher heterogeneity of risk preferences compared to the risk itself (cf. CoHEN and EINAV, 2007). 
insurer: $\left(\lambda(e, \bar{m}) ; \lambda^{\prime}(e, \bar{m})>0, \lambda^{\prime \prime}(e, \bar{m})<0\right)$. Without loss of generality, the distribution of the signal $\lambda$ conditional on the effort level $e$ and the level of insurance monitoring activity $m$ is associated with a continuous uniform distribution on the interval $\lambda \in(0,1)$. A value of $\lambda$ close to zero means that the value of information is low. However, the patient really makes major prevention efforts if the signal $\lambda$ runs against $1\left(\lambda(e, m) \rightarrow 1\right.$ for $\left.e \rightarrow e^{*}\right)$.

There exist interrelations between $e$ and $m$ that influence the parameter $\lambda$. For the sake of simplification, we assume that the impact of additional monitoring investments is contingent on the hidden level of prevention effort, e. g. $\partial \lambda /\left.\partial m\right|_{e \rightarrow 0}>0$ or $\partial \lambda /\left.\partial m\right|_{e \rightarrow \infty}=0$. Altogether, $\partial \lambda /\left.\partial m\right|_{e>0}>0$ holds and therefore $\partial^{2} \lambda / \partial m^{2}<0$ will be feasible for addressing diminishing returns to additional monitoring efforts. Hence, with perfect prevention, there is no need to monitor the patient's activities. This result resembles the first-best case with perfect information, where no cost-sharing strategy is needed to induce additional prevention efforts.

The insurer uses the received information signal to adapt the coverage level contingent on the perceived level of lambda. With better information, the patient receives a higher amount of coverage and vice versa. Hence, using this information results in a form of individual cost-sharing: $x \cdot \lambda(e, m) \equiv \bar{K}<K^{\max }$. This means that bad risks with respect to prevention have lower coverage. Simultaneously, they face higher co-payments and therefore pay a reduced premium. With a bad information flow $(\lambda \rightarrow 0)$, the patient has to bear more of the costs of the monetary health shock $L$ and the cost sharing is high. In other words, the price for the medical treatment directly borne by the patient rises if the information perceived by the insurer and the information revealed by the patient is deteriorating. Even in the case where the insurer sets the coverage $x$ to the first-best level $K^{\text {max }}$, there remains a fraction of treatment cost which the patient has to bear because the information level $\lambda$ is strictly smaller than 1 . Consequently, there is always a form of cost-sharing in a situation with asymmetric information. Hence, the patient's expected utility is given by:

$$
\max _{e} E U=p(e) \cdot U[W-\pi-L+x \lambda(e, m)]+(1-p(e)) \cdot U[W-\pi]-C(e)
$$

The first-order condition to this problem is

$$
\frac{\partial E U}{\partial e} \Rightarrow p^{\prime}(e) \cdot\left(U_{S}-U_{H}\right)+p(e) \cdot U_{S}^{\prime}\left(\frac{\partial \lambda}{\partial e} x\right)=C^{\prime}
$$


In contrast to equation (5), the term indicating the indirect effect of higher $e$ through the insurance premium is missing. Instead, the patient considers the effect of his prevention on the information transmission and therefore on his cost sharing. In consequence, the second best case $\hat{e}<e^{*}$ holds. Referring to (8), we can infer that, due to diminishing returns, the gain in utility of an additional unit of prevention will be lower if the initial level of $e$ is high. This means that for patients with high prevention compliance the rising costs of additional prevention activities outweigh the benefit.

Finally, the difference between equation (5) and (8) reveals that under asymmetric information the effect of the zero profit condition is missing. Even if the insurer has conducted some monitoring activities and is perfectly informed about the preventive behaviour, the patient does not consider the premium effects of monitoring. Instead, in (8) the patient considers the influence on the received level of treatment described above. Altogether, we can infer two problems for the contract environment: First, in consequence of the information flow, the insurer cannot directly observe the patient's prevention activity. Second, a worsening information transmission goes along with deteriorating remedies for controlling the patient's activities.

Proposition 1: Even in the case in which the information transmission is near the first best, the patient neglects the effect of his prevention activity for the zero-profit-condition of the insurance company. This results in a lower level of prevention as long as the information distribution is imperfect $(\lambda<1)$.

We can use a re-written equation (7) to discuss the case of non-insurance on prevention activity. When there is no insurance at all the patient maximises: ${ }^{10}$

$$
\max _{e} E U=p(e) \cdot U[W-L]+(1-p(e)) \cdot U[W]-C(e)
$$

The resulting first-order condition is:

$$
\frac{\partial E U}{\partial e} \Rightarrow p^{\prime}(e) \cdot\left(\bar{U}_{S}-\bar{U}_{H}\right)=C^{\prime}
$$

9 This result resembles ideas of time-inconsistency where there is a bias in information perception due to strategic intolerance. This effect is not independent of the costs of being intolerant (cf. Brocas and Carillo, 2000).

10 We denote $U[W-L]$ with $\bar{U}_{S}$ and $U[W]$ with $\bar{U}_{H}$. 
In comparison to (8) the marginal gain by additional prevention activities must exceed the benefit, which the patient can achieve when he is insured, because prevention is the only mean for the patient to reduce the risk of potential health loss. However, the net value is definitely lower than in the insurance case as long the patient is risk-averse. Hence, not to be insured indicates the lower bound of welfare a patient can get.

$$
\left|p^{\prime}(e)\left(\bar{U}_{S}-\bar{U}_{H}\right)\right|>\left|p^{\prime}(e)\left(U_{S}-U_{H}\right)\right|
$$

Proposition 1a: If the patient is not insured, he has to cover all the costs of an exogenous health shock. Then, the patient has to undertake more prevention activities to reduce the negative impact of a health shock. Because of the missing insurance coverage, the overall welfare is less.

\subsection{The Impact of the Insurance Parameters}

From the results stated above, it follows that a lack of information as well as problems of appropriate organisational structures influence the co-production of health by the patient. From the insurer's point of view, the outcome depends not only on the (expected) agent's effort but also on a monitoring component. The insurer's break-even-condition reflects this effect: ${ }^{11}$

$$
\pi=p(e) \cdot \lambda(e, m) \cdot x+m
$$

The zero profit condition in the asymmetric case depends on the signal $\lambda$ and therefore reflects the insurer's perception of the patient's post-contract behaviour. Moreover, monitoring activities are produced at constant marginal costs.

By differentiating equation (11) with respect to the coverage level $x$ one gets:

$$
\frac{\partial \pi}{\partial x}=p(e) \cdot \lambda(e, m)
$$

Here, the influence of the coverage on the insurance premium is also contingent on the weight set by the probability of illness and by the perceived information distribution depicted by the parameter $\lambda$.

11 Similar to the assumption of Shavell (1979) the costs of screening are constant and only contingent on the probability $p(e)$. 
Totally differentiating equation (8) and taking the result of (12) gives the "costsharing effect". The parameter $x$ depicts the level of coverage the insurer wants to guarantee which equals $K$ in the first-best case. As mentioned above, a reduction in $x$ incorporates both forms of "cost-sharing".

$$
\frac{d \hat{e}}{d x}=-\frac{p^{\prime}(e) \cdot U_{S}^{\prime}\left[-\frac{\partial \pi}{\partial x}+\lambda(e, m)\right]-p^{\prime}(e) \cdot U_{H}^{\prime}\left[-\frac{\partial \pi}{\partial x}\right]}{\Omega}+\frac{p(e) \cdot U_{s}^{\prime \prime}\left[-\frac{\partial \pi}{\partial x}+\lambda(e, m)\right] \cdot \frac{\partial \lambda}{\partial e} x+p(e) \cdot U_{s}^{\prime} \frac{\partial \lambda}{\partial e}}{\Omega}
$$

The total effect of a higher level of coverage on preventive activities is ambiguous. Therefore, the impact of a change in $x$ must be simultaneously explored with a change in the level of $\lambda$ within the range $\lambda \in(0,1)$. Following the computation given in the appendix, we can conclude:

$$
\begin{aligned}
& \frac{d \hat{e}}{d x}<0, \text { iff } \lambda \rightarrow 1 \\
& \frac{d \hat{e}}{d x}>0, \text { iff } \lambda \rightarrow 0
\end{aligned}
$$

Proposition 2: The lower the flow of information $\lambda$, the more the patient wants to increase his own prevention activity given a high level of coverage.

This result resembles the idea that higher cost sharing rises the interest for enhancing self-protection efforts. As soon as a threshold level of $\lambda$ is passed the impact of additional coverage reduces the interest for doing primary prevention. The reason behind this is that with a higher guaranteed coverage level the opportunity costs for being non-compliant are lower and thus rendering non-preventive behaviour "cheaper".

In order to complete the analysis of the influence of the contract parameters on prevention, we look at the monitoring activities of the insurer $(m)$. With regard to our assumption, the informed patient can anticipate the efforts of the insurer. Therefore, it is rewarding to show the relation between the patient's prevention effort and the costs of monitoring, which could be a proxy for the insurer's own effort of monitoring ("monitoring effect"). 


$$
\begin{aligned}
& \frac{d \hat{e}}{d m}=-\frac{p^{\prime}(e) \cdot U_{S}^{\prime}\left[-\frac{\partial \pi}{\partial m}+\frac{\partial \lambda}{\partial m} x\right]-p^{\prime}(e) \cdot U_{H}^{\prime}\left[-\frac{\partial \pi}{\partial m}\right]}{\Omega} \\
& +\frac{p(e) \cdot U_{s}^{\prime \prime}\left[-\frac{\partial \pi}{\partial m}+\frac{\partial \lambda}{\partial m} x\right] \frac{\partial \lambda}{\partial e} x+p(e) \cdot U_{s}^{\prime} \frac{\partial^{2} \lambda}{\partial e \partial m} x}{\Omega}
\end{aligned}
$$

The effect of $m$ on $\hat{e}$ depends on the perception of monitoring activities by the patient $(\partial \lambda / \partial m)$ and the level of $e$ (see appendix):

$$
\frac{d \hat{e}}{d m}<0, \text { iff } \frac{\partial^{2} \lambda}{\partial e \partial m}<0 \text { and } m \text { small }
$$

Proposition 3: The impact of monitoring activities on prevention depends on the level of e (and therefore on the risk of illness) and the interaction of $\hat{e}$ and $\mathrm{m}$ in the information transmission.

Given that monitoring and prevention interact as strategic substitutes $\left(\partial^{2} \lambda / \partial e \partial m<0\right)$, higher monitoring activities lead to disincentives for preventive behaviour if the level of monitoring is sufficiently small. Instead, if we observe $e$ and $m$ to be strategic complements, for a positive impact of $m$ on $e$ it is necessary that higher monitoring activities lead to a reduction of income after treatment. This again raises the opportunity costs of being non-preventive for the patient.

\subsection{Extension: Income-Related Contributions}

Up to now, we have referred to a traditional health insurance model in which the patient has to pay risk-orientated premiums. But many health care systems, for instance Germany, prefer to use income-related contributions (social health insurance). All patients face a 'premium' that is individually related to income per person with no direct relationship to individual health care risks and treatment expenditures. For the sake of simplification, we suppose that the insurer covers all persons in the society who may differ in income but are homogeneous in risk. Moreover, the signal $\lambda(e, m)$ is similar for all patients. The patients are classified into two different income groups $W_{\alpha} \neq W_{\beta}$. The individual contribution directly depends on the overall health care costs as well as on the available income of all other insurants. Then, the patient's costs for being insured are: 


$$
\pi_{s}=\tau \cdot W_{i}
$$

For the fraction $\tau$ the following equation holds:

$$
\tau=\frac{\alpha p(e)_{\alpha} K+\beta p(e)_{\beta} K+m}{\alpha W_{\alpha}+\beta W_{\beta}}
$$

Here, $\alpha$ and $\beta$ are the shares of both income groups in the insured population. For the sake of simplification, all patients are homogeneous in risk, i.e. $p_{\alpha}=p_{\beta}$. In the asymmetric case, the patient maximises his own prevention effort comparable to equation (8). For the "cost sharing effect", the following case differentiation is necessary (see appendix):

$$
\begin{aligned}
& \left.\frac{d \hat{e}}{d x}\right|_{\pi_{S}}<\left.\frac{d \hat{e}}{d x}\right|_{\pi} \\
& \left.\frac{d \hat{e}}{d x}\right|_{\pi_{S}}>\left.0 \wedge \frac{d \hat{e}}{d x}\right|_{\pi}>0 \quad \forall \lambda \rightarrow 0 \\
& \left.\frac{d \hat{e}}{d x}\right|_{\pi_{S}}<\left.0 \wedge \frac{d \hat{e}}{d x}\right|_{\pi}<0 \quad \forall \lambda \rightarrow 1
\end{aligned}
$$

As for the risk-orientated premiums, the effect of an increased coverage depends on the information flow. If the information signal $\lambda$ is close to zero, a positive effect on the prevention activity is induced. Compared to risk-orientated premiums, the magnitude of the effect is smaller. For the case that $\lambda \rightarrow 1$, the impact of higher coverage is negative. Moreover, the reduction of preventive activities is higher if income-related contributions are charged. Hence, the patients do not anticipate the induced costs of lower prevention levels on the overall insurance costs. Therefore, a higher coverage level will incentivise the patient to do less prevention activities in the income-orientated case.

Referring to the monitoring effect the following result holds if income-related contributions are valid:

$$
\begin{aligned}
& \left.\frac{d \hat{e}}{d m}\right|_{\pi_{S}}<\left.\frac{d \hat{e}}{d m}\right|_{\pi} \wedge \\
& \left.\frac{d \hat{e}}{d m}\right|_{\pi_{S}}<\left.0 \wedge \frac{d \hat{e}}{d m}\right|_{\pi}<0 \quad \forall \frac{\partial^{2} \lambda}{\partial e \partial m}<0
\end{aligned}
$$


Given strategic substitutes, the effects of additional monitoring always reduce the patient's incentive to increase his prevention activities. Both effects hold for risk-orientated premiums as well as for income-orientated contributions. If the insurer charges income-orientated contributions, the patient neglects the monitoring effect upon his insurance contributions. Hence, an increase in monitoring will also induce the patient to reduce his prevention activities to a higher degree than it does in the risk-orientated case.

Proposition 4: In case of income-related contributions, the cost-sharing effect and the monitoring effect lead to less prevention activities compared to riskorientated premiums.

With income-related contributions, patients will never pay the full treatment costs, and therefore the incentives are distorted.

\subsection{Conclusion of the Theoretical Model}

If information transmission is nearly perfect and if information between the insurer and the patient is asymmetric, the level of preventive activities depends negatively on the coverage. Hence, a higher level of coverage lowers the incentive for self-protection. Moreover, if income-orientated contributions are set, the impact of the premium effect vanishes, i.e. the efficacies of insurer's contract parameters are reduced.

In consequence, the patient faces lower opportunity costs when reducing prevention activities in comparison to the risk-orientated case. In addition, it can be reasoned that an increase in monitoring activities can partly substitute a stronger cost-sharing regime in both premium regimes. This effect is contingent on strategic dependence of prevention and monitoring in the information transfer.

To sum up the above findings, asymmetric information has remarkable consequences for the individual's behaviour and the design of the contract parameters. First of all, the level of prevention declines if the insurance company is unable to observe the preventive activity. In consequence, if the patient neglects the costs of doing prevention and the impact of doing prevention on insurance premium involved he will be incentivised to substitute prevention with a higher level of coverage.

Moreover, there is also need for an information environment that can be influenced by the contract between insurer and insurant. The insurer has an additional parameter for governing the patient's behaviour by means of deciding on monitoring activities. Therefore, he can partly substitute cost sharing 
with more monitoring efforts that could be organised in forms of managed care like disease management or case management. These findings correspond with the results outlined in the literature describing the importance of good mutual compliance. $^{12}$

As mentioned before, the model concentrates on the effects of changes in contract parameters on the prevention decision. There is no explicit modelling of the time structure. Hence, in the case of simultaneous actions of insurer and patient, only the short-term effects can be analysed. Moreover, as we focus on changes in existing insurance contracts, problems of adverse selection are omitted. On this basis, the emphasis of the analysis is on the current prevention behaviour.

\section{The Empirical Investigation}

In the theoretical part, it has been outlined that both monetary parameters and complementary informational structures enforce the effectiveness of prevention efforts. The parameter $\lambda$ has indicated that some form of prevention environment is necessary for discussing the effectiveness and the efficiency for prevention. Within our theoretical analysis, we have concentrated on discussing the marginal effects of insurance parameters on the patient's prevention decision. Therefore, the empirical analysis concentrates on the patient's role in prevention activities. In detail, we look on monetary and non-monetary prevention activities of patients that could improve their individual health stock by self-protection activities.

From our theoretical findings, the following two testable hypotheses can be derived:

Hypothesis 1: Prevention behaviour differs with respect to the underlying insurance system. A reduction in the insurance coverage enhances prevention behaviour contingent on a given level of information and the impact of the premium effect.

The first hypothesis describes the findings that the individual's prevention decision depends on the insurance parameters (i.e. a cost-sharing effect). With regard to the theoretical results, especially individuals with a lower willingness to engage in primary prevention react to monetary incentives. In general, the effects of

12 Cf. Dracup and Meleis (1982) or Greenlund et al. (2000). Greenlund et al. stress the importance of the positive impact on the patient's effort when there is a consistent and truthful behaviour of the clinician. 
contract parameters on the prevention decision depend on the underlying insurance system. Without any insurance, individuals have the highest incentives to engage in prevention activities. Insured patients react to increases in cost sharing. However, the effects are more tangible in a system with risk-orientated premiums than in social health insurance systems with income-related contributions. In the latter case, patients will not correctly anticipate the opportunity costs of doing prevention. In consequence, we expect that at a high level of coverage a change in (income-orientated) premiums will hardly effect prevention efforts, and vice versa. This is important because in many countries private and public systems exist in parallel. In Germany, for instance, social health insurance and private health insurance differ in varying co-payment schemes, with respect to their coverage levels and in the way contributions and premiums are charged. Hence, we would expect different effects for the prevention decision.

Hypothesis 2: Non-monetary aspects affect the individual perception of prevention. Hence, information is a key for changes in behaviour.

Referring to the theoretical model, we have to consider that institutional incentives are set contingent on the perceived information about the prevention efforts. Considering the literature on patient-physician relationship, we can state that the education level is one key factor that enhances the informational environment health care provider and patient share (cf. Maurer, 2009 or Vick and SCOTT, 1998). Hence, we can assume that the parameter $\lambda$ will increase in accordance with the basic level of education.

Second, the individual's health status can be viewed as a further driving factor of prevention behaviour. It summarises on the one hand the results of preventive actions in the past and on the other hand the experiences with medical care. However, the impact of health status on the information transmission remains unclear a priori.

Our variable of interest is the primary preventive behaviour of a patient. This is a multidimensional construct depending on a variety of health behaviours that cannot be observed directly. Therefore, we have to reformulate our notion of prevention. Instead of a general concept of prevention, we use a specific form of health relevant behaviour, namely the attitude towards smoking. In detail, we look at the individual's decision to change this behaviour. As noted before, in our empirical specification we use a discrete change in behaviour for measuring prevention instead of a continuous variable. Starting with a set of individuals who are current smokers at the beginning of the relevant year, we can observe their decision to quit or to go on smoking in the years following. 
The empirical literature on health related behaviour and especially smoking is huge. Kenkel (1991) for example analyses the relation between school attendance, smoking, alcohol consumption and exercises. He uses the answer to the question whether an individual is aware of the health risks related to a specific behaviour as an explanatory variable. As a result, better health knowledge leads individuals to behave healthier, e.g. to smoke less. An instrumental-variable approach in the estimation of the number of cigarettes smoked is presented by Mullahy (1997). After correcting for unobserved heterogeneity, cigarette price, income age and education can be identified to influence the amount of smoking. Forster and Jones (2001) investigate the role of tobacco taxes in starting and quitting smoking. Using British data, they find that higher taxes lead to a lower consumption of tobacco products. The effect of health behaviours on the individual's perception of health is at the core of a paper by ConTOYANNIs and Jones (2004). They find that non-smokers have a higher perception of the individual health status than smokers have. Kenkel et al. (2006) look at the educational effects on the decision to smoke. Using high school competition and $\mathrm{GED}^{13}$ receipt as possible sources for a good health behaviour, they show that a high school degree goes along with a lower probability to smoke but has no effect on other health variables like obesity. Cowell (2006) investigates the future effects of current health behaviours and finds that future opportunity costs affect the decision to smoke. Moreover, the number of schooling years has a negative impact on cigarette smoking. By using dummy variables for different educational degrees, he finds a negative gradient in higher education.

\subsection{Data}

The data we use is from the German Socio-Economic Panel (SOEP), a representative longitudinal study of private households in Germany. ${ }^{14}$ Explicitly, we use the years 1995-2002. With respect to our indicator for primary prevention, we make use of questions of the year 2002 in which respondents are asked to report the year they started and stopped smoking. With this information, we construct a variable that for each year of our analysis indicates whether the individual smokes or not. Starting with the year 1995, our dataset consists of 2,130 individuals that are smokers at the beginning of that year. Within the whole

13 General Educational Development (or GED) tests are a group of five subject tests which, when passed, certify that the taker has American or Canadian high school-level academic skills.

14 The data used in this publication were made available to us by the German Socio-Economic Panel Study (SOEP) at the German Institute for Economic Research (DIW), Berlin. 
period covered, 2.21 percent quit smoking. This means that every single year a small percentage of respondents stop smoking. In the last year of our sample, only 1,754 individuals state to be smokers. Therefore, 406 individuals did indeed quit smoking, resulting in 15,726 observations for the eight years.

The independent variables can be divided into three different categories (see Table 1): The first category contains predisposing variables like gender and nationality as well as five age dummies. The additional variables 'partnership' and 'children' are indicators for the family status of the respondent. All of these variables are binary ones. In the second category, socioeconomic variables are included to explain general economic conditions. One variable determines the money disposable for consumer and health care goods, namely the household income. Here, we use the logarithm of the net household income to correct for the skewness of the density function. As household size varies, we use the household equivalent income. Moreover, we include a dummy variable stating whether an individual expects serious economic worries in the future.

Furthermore, educational variables are included. We use the SOEP version of the International Standard Classification of Education (ISCED) where schooling as well as vocational training is considered. Last, we include variables concerning workload, unemployment and a regional dummy for Eastern Germany that should measure remaining differences in preventive behaviour. Health and insurance variables constitute the third category. Here, the respondent's insurance status is included. Our reference group consists of those insured in the German Statutory Health Insurance (SHI). ${ }^{15}$

We include dummy variables for the insurance status: an individual may not have any health insurance, he has a SHI-coverage with supplemental insurance, or he is comprehensively insured on a private scheme. Both, fully private and supplemental coverage often go along with a broader coverage and a cost-sharing structure that differs from that in the SHI in which co-payments are relatively unimportant. In detail, contracts for full private insurance often have different forms of cost sharing like co-insurance or deductibles that are not common in the SHI ${ }^{16}$ Moreover, as supplemental insurance results in a broader coverage, this higher level of insurance goes along with a reduction in cost sharing. In the SHI

15 In the SHI system, the benefits-in-kind principle is used and the health plans transfer money to the physician's associations which distribute the money according to the treatment. In the private health insurance industry, the cost reimbursement principle is implemented. Thereby, private insurers have information about the received treatment and the costs.

16 From an international perspective, the co-payments in the German private health insurance sector are still comparatively low. 
Table 1: Description of the Variables

\begin{tabular}{|c|c|}
\hline Variable & description \\
\hline non-smoker & non-smoker at the beginning of the year yes/no \\
\hline \multicolumn{2}{|l|}{ Predisposing variables } \\
\hline age $<30$ & respondent less than 30 years old yes/no (reference group) \\
\hline age $30-45$ & respondent 30 to 45 years old yes/no \\
\hline age $46-60$ & respondent 46 to 60 years old yes/no \\
\hline age $61-75$ & respondent 61 to 75 years old yes/no \\
\hline age $>75$ & respondent older than 75 years yes/no \\
\hline female & $1=$ female, $0=$ male \\
\hline partner & living together with a partner yes/no \\
\hline foreigner & children under 16 in household yes/no \\
\hline children $<16$ & nationality not German yes/no \\
\hline \multicolumn{2}{|l|}{ Socioeconomic variables } \\
\hline Eastern Germany & living in Eastern Germany yes/no \\
\hline ISCED_1+2 & $\begin{array}{l}\text { Pre-primary education, primary education or first stage of basic } \\
\text { education yes/no (reference group) }\end{array}$ \\
\hline ISCED_2 & Lower secondary or second stage of basic education yes/no \\
\hline ISCED_3 & (Upper) secondary education yes/no \\
\hline ISCED_4 & Post-secondary non-tertiary education yes/no \\
\hline ISCED_5 & First stage of tertiary education yes/no \\
\hline ISCED_6 & Second stage of tertiary education yes/no \\
\hline eq. hh-income & Log equivalent household net income in $€$ \\
\hline economic worries & strong worries about own economic situation yes/no \\
\hline working time & number of hours worked regularly \\
\hline working time sq. & number of hours worked regularly sq \\
\hline unemployed & unemployed yes/no \\
\hline \multicolumn{2}{|c|}{ Insurance and health variables } \\
\hline no insurance & neither private nor social health insurance yes/no \\
\hline SHI & Statutory Health Insurance yes/no (reference group) \\
\hline supplementary ins. & SHI with private supplemental insurance yes/no \\
\hline private insurance & fully privately insured yes/no \\
\hline health status & health capital stock \\
\hline age started smoking & age at which the respondent first smoked \\
\hline
\end{tabular}


Table 2: Descriptive Statistics for the First Wave (1995): 2130 Observations

\begin{tabular}{|c|c|c|c|c|}
\hline Variable & Mean & Std. Dev. & Min & Max \\
\hline non-smoker & 0.0221 & 0.1469 & 0 & 1 \\
\hline age $<30$ & 0.2690 & 0.4436 & 0 & 1 \\
\hline age $31-45$ & 0.4343 & 0.4958 & 0 & 1 \\
\hline age $46-60$ & 0.2258 & 0.4182 & 0 & 1 \\
\hline age $61-75$ & 0.0657 & 0.2479 & 0 & 1 \\
\hline age $>75$ & 0.0052 & 0.0717 & 0 & 1 \\
\hline female & 0.4272 & 0.4948 & 0 & 1 \\
\hline partner & 0.7465 & 0.4351 & 0 & 1 \\
\hline foreigner & 0.1667 & 0.3728 & 0 & 1 \\
\hline children $<16$ & 0.4831 & 0.4998 & 0 & 1 \\
\hline Eastern Germany & 0.2826 & 0.4504 & 0 & 1 \\
\hline ISCED_1 + 2 & 0.0615 & 0.2403 & 0 & 1 \\
\hline ISCED_2 & 0.1873 & 0.3903 & 0 & 1 \\
\hline ISCED_3 & 0.5230 & 0.4996 & 0 & 1 \\
\hline ISCED_4 & 0.0436 & 0.2044 & 0 & 1 \\
\hline ISCED_5 & 0.0573 & 0.2324 & 0 & 1 \\
\hline ISCED_6 & 0.1272 & 0.3333 & 0 & 1 \\
\hline eq. hh-income & 7.6932 & 0.4316 & 4.9416 & 10.1165 \\
\hline economic worries & 0.2413 & 0.4280 & 0 & 1 \\
\hline working time & 28.1770 & 20.4842 & 0 & 80 \\
\hline working time sq. & 1213.32 & 1057.319 & 0 & 6400 \\
\hline unemployed & 0.0770 & 0.2666 & 0 & 1 \\
\hline no insurance & 0.0038 & 0.0612 & 0 & 1 \\
\hline SHI & 0.9249 & 0.2636 & 0 & 1 \\
\hline supplementary ins. & 0.0432 & 0.2033 & 0 & 1 \\
\hline private insurance & 0.0319 & 0.1758 & 0 & 1 \\
\hline health status & 0 & 1 & -4.8857 & 0.73068 \\
\hline age started smoking & 17.9478 & 4.5645 & 7 & 54 \\
\hline
\end{tabular}

these services are not included. Consequently, 100 percent are charged. Finally, to capture health effects of long-time smoking, we include the health capital stock of the individual in relation to others in the relevant year. This health variable gives some information about the individual's experience and might be related to 
changes in prevention behaviour. With this construction, we analyse the effect of health status on health relevant behaviour. Additionally, the age at which the individual started smoking serves as a proxy for the duration of smoking in years. The descriptive statistics for the first year in the sample is given in Table 2 .

\subsection{Estimation Method}

We study the decision to quit smoking by estimating discrete-time hazard functions. In consequence, we want to analyse the time at risk for the event "quit smoking". In detail, we apply the stock-sampling approach specified by Jenkins (1995), meaning that we use an unbalanced panel data structure (cf. WoOLDRIDGE, 2002, p. 700). For the first period $t=\tau$, only those individuals that currently smoke are in the sample. Then, for the following periods, we drop all those individuals that quit smoking. Over the whole sample period, 406 of the original 2130 individuals changed their health related behaviour. Hence, we observe two types of individuals. First, those who quit smoking in $t=\tau+s_{i}$ and second, those for which the observation period ends in $t=\tau+s_{i}$ before they might have quit (interview data). In the first case, one can speak of complete duration data (complete spell $\delta_{i}=1$ ), whereas in the second case, we have censored duration data $\left(\delta_{i}=0\right)$.

For the estimation at hand, the probability to quit smoking at time $t$ incorporates information on the duration distribution. Following Jenkins (1995), the discrete-time hazard rate $h_{i t}$ is:

$$
h_{i t}=\operatorname{Pr}\left(T_{i}=t \mid T_{i} \geq t, X_{i t}^{\prime} \beta\right)
$$

Here, $X_{i t}$ is a vector of covariates that varies over time, and $T_{i}$ is a discrete random variable representing the time at which the smoking period ends. Then, the conditional probability of observing an incomplete spell at a given time period is given by:

$$
\operatorname{Pr}\left(T_{i}>t+s_{i} \mid T_{i}>\tau-1\right)=\prod_{t=\tau}^{\tau+s_{i}}\left(1-h_{i t}\right)
$$

The conditional probability of observing the event history of someone completing a spell is:

$$
\operatorname{Pr}\left(T_{i}>t+s_{i} \mid T_{i}>\tau-1\right)=\left(\frac{h_{i \tau+s_{i}}}{1-h_{i \tau+s_{i}}}\right) \prod_{t=\tau}^{\tau+s_{i}}\left(1-h_{i t}\right)
$$


For the whole sample, the resulting log-likelihood of observing the smoking history data can be expressed as:

$$
\log L=\sum_{i=1}^{n} \delta_{i} \log \left(\frac{h_{i \tau+s_{i}}}{1-h_{i \tau+s_{i}}}\right)+\sum_{i=1}^{n} \sum_{t=\tau}^{\tau+s_{i}} \log \left(1-h_{i t}\right)
$$

To simplify the estimation method, Jenkins defines the variable $y_{i t}=1$ if $t=\tau+s_{i}$ and $\delta_{i}=1$ and $y_{i t}=0$ otherwise. Hence, for all individuals who carry on smoking during the complete sample period $y_{i t}=0$ and for those who quit smoking $y_{i t}=0$ for the periods prior to the one when they stop smoking, where $y_{i t}=1$. Then, the $\log$-likelihood corresponds to the following expression: ${ }^{17}$

$$
\log L=\sum_{i=1}^{n} \sum_{t=\tau}^{\tau+s_{i}} y_{i t} \log \left(\frac{h_{i t}}{1-h_{i t}}\right)+\sum_{i=1}^{n} \sum_{t=\tau}^{\tau+s_{i}} \log \left(1-h_{i t}\right)
$$

Hence, the estimation is carried out using a standard log-likelihood method, but the dataset is organised differently, using the stock sampling approach. This means that for each individual there are as many data rows as there are time intervals for the risk of the event "quit smoking" for each person (cf. Jenkins, 1997, p. 112). ${ }^{18}$

For a complete specification, the expression for the hazard rate has to be determined. Jenkins uses a complementary log-log hazard rate that is defined as follows: ${ }^{19}$

$$
\begin{aligned}
h_{i t} & =1-\exp \left\{-\exp \left[\theta(t)+\beta^{\prime} X_{i t}\right]\right\} \\
& \Leftrightarrow \log \left[-\log \left(1-h_{i t}\right)\right]=\theta(t)+\beta^{\prime} X_{i t}
\end{aligned}
$$

Here, $\theta(t)$ is the baseline hazard. The model allows for a non-parametric form of this baseline hazard with a separate dummy variable for each duration interval

17 It is worth mentioning that the above log-likelihood function has the same form as a standard $\log$-likelihood when estimating models for a binary variable ( $y_{i t}$ ) (cf. Jenkins, 1995, p. 134).

18 For the specification presented, it follows that there are $\tau+s_{i}$ rows for each individual $i=1, \ldots, n$.

19 One main property of this specification is that the resulting model is the discrete-time counterpart of an underlying continuous-time proportional hazards model (cf. JENKINs, 1997, p. 134). 
(cf. Jenkins, 1997, p. 110). ${ }^{20}$ This is done by including a dummy variable for each year, with 1995 as reference year. Moreover, a second version of the discrete-time proportional hazards model incorporates a gamma-distributed random variable to describe unobserved heterogeneity between individuals.

\subsection{Modelling the Individual's Health Stock}

According to our second hypothesis, individual health status plays a crucial role in determining preventive behaviour. In the SOEP data, measures of health, like self-assessed health, are included. Such measures of health and their validity have caused a considerable debate (cf. Jones, 2007, p. 21). Concerning these variables, the self-assessed health variable might be vulnerable to a reporting bias because of anticipation and measurement errors (cf. HAGAN et al., 2006, p. 11 and Hernández-Quevedo et al., 2005, p. 4). The original self-assessed health variable is a five-point scale variable ranging from very good to bad. To correct for a possible bias, we apply a technique proposed by DisNeY et al (2006). We estimate a model of self-assessed health as a function of objective health measures $m$, e.g. the utilisation of health care or physical and mental well-being (cf. Disney et al., 2006, pp. 625). First, we can write the unobservable health status as a function of $x$ and $m$ :

$$
\eta_{i t}=x_{i t}^{\prime} \beta+m_{i t}^{\prime} \gamma+u_{i t}
$$

Instead of $\eta_{i t}$, self-assessed health $H_{i t}$ is observed in the data set. The latent health stock $H^{*}$ is the counterpart of the observed self-assessed health and is a function of the unobservable health status $\eta_{i t}$ and a reporting error $\varepsilon_{i t}$ :

$$
H_{i t}^{*}=\eta_{i t}+\varepsilon_{i t}
$$

The latent health variable can be linked to the dichotomous indicator $H_{i t}$ using the following observation mechanism:

$$
H_{i t}^{*}=j \text { if } \mu_{j-1}<H_{i t}^{*}<\mu_{j}, j=1, \ldots, 5
$$

20 Alternatively, using a Weibull distribution or a Cox-hazard model to estimate the model leads to comparable results but assumes a specific baseline hazard. The main advantage of our approach is that no explicit functional form for the baseline hazard has to be specified and that this non-parametric form also allows for a non-monotonic function. 
Equation (29) shows that our observable health variable takes the value $j$ if the latent health stock lies between the two thresholds $\mu_{j-1}$ and $\mu_{j}$. Combining the observation mechanism with equation (27), the model can be estimated using ordered probit techniques. Following Disney et al. (2006), we estimate the health stock for each wave separately, using the wave specific values of $m$ and $x$. Applying the predicted values stemming from these estimations, we can normalise the health stock using a $z$-transformation. This yields a health capital stock that has a zero mean and a constant variance of one for each wave. Furthermore, positive values of our health capital stock variable indicate that the respondent's health is above the sample mean in this period.

\subsection{Results}

The estimation results for the hazard model that incorporates individual heterogeneity are summarised in Table 3 . In the second column, the value of the estimated coefficient is presented. Columns three and four show the z-value and the p-value and the last column gives the hazard ratio. A value greater than one means that the specific factor increases the probability of quitting smoking, whereas a value below one denotes the reverse interpretation. Two age dummies show a significant positive influence. This means that older people (up to 75 years) tend to stop smoking more often than younger people do. ${ }^{21}$ There exist differences between our reference group (younger than 30) and the age classes above. This effect may be due to illness experiences related to smoking and could be interpreted as an effect of a higher risk aversion. Moreover, it is remarkable that people in Eastern Germany have a higher probability of stopping smoking. In our sample, 28 percent of the smokers in the year 1996 live in Eastern Germany compared to 19 percent for the whole population, which means that this group has a higher affinity for smoking.

In the group of insurance variables, the variable "no insurance" shows a weakly significant positive effect. This means that individuals without any insurance coverage at all have to invest more in the health production, which resembles the result from Proposition 1a. As this result supports Hypothesis 1, the insignificant coefficients of supplementary and private insurance show that there seem to be no differences in insurance status between SHI, supplemental and private

21 It is important to mention that we do not have any information about the reasons why people quit smoking, i.e. we have no data on whether the decision might be physician initiated, or not. In other words, whether quitting smoking is related to prevention or compliance cannot be tested. 
Table 3: Estimation Results

\begin{tabular}{|c|c|c|c|c|}
\hline Hazard & coefficient & $\mathrm{Z}$ & $\mathrm{P}>|\mathrm{z}|$ & hazard $\mathrm{r}$. \\
\hline \multicolumn{5}{|c|}{ Predisposing and family variables } \\
\hline age $31-45$ & 0.0708 & 0.26 & $(0.797)$ & 1.0733 \\
\hline age $46-60$ & $0.7471^{*}$ & 1.82 & $(0.069)$ & 2.1109 \\
\hline age $61-75$ & $0.9265^{*}$ & 1.69 & $(0.092)$ & 2.5257 \\
\hline age $>75$ & 1.5001 & 1.52 & $(0.127)$ & 4.4822 \\
\hline female & -0.2637 & -0.98 & $(0.329)$ & 0.7682 \\
\hline partner & -0.0755 & -0.31 & $(0.755)$ & 0.9272 \\
\hline foreigner & $0.6934^{*}$ & 1.77 & $(0.077)$ & 2.0005 \\
\hline children $<16$ & -0.2305 & -1.04 & $(0.300)$ & 0.7941 \\
\hline \multicolumn{5}{|l|}{ Socioeconomic variables } \\
\hline Eastern Germany & $0.6158^{*}$ & 1.89 & $(0.059)$ & 1.8512 \\
\hline ISCED_2 & 0.7543 & 1.46 & $(0.144)$ & 2.1262 \\
\hline ISCED_3 & $1.1052^{* *}$ & 2.15 & $(0.032)$ & 3.0197 \\
\hline ISCED_4 & 0.9655 & 1.55 & $(0.120)$ & 2.6261 \\
\hline ISCED_5 & $1.9209^{* * *}$ & 2.73 & $(0.006)$ & 6.8270 \\
\hline ISCED_6 & $2.0384^{* * *}$ & 3.25 & $(0.001)$ & 7.6787 \\
\hline eq. hh-income & 0.0026 & 0.01 & $(0.991)$ & 1.0026 \\
\hline economic worries & $-0.3701^{* *}$ & -2.02 & $(0.043)$ & 0.6907 \\
\hline working time & $-0.0279^{* *}$ & -1.99 & $(0.046)$ & 0.9725 \\
\hline working time sq. & $0.0006^{* *}$ & 2.43 & $(0.015)$ & 1.0006 \\
\hline unemployed & 0.0901 & 0.29 & $(0.775)$ & 1.0942 \\
\hline \multicolumn{5}{|l|}{ Insurance and health } \\
\hline no insurance & $1.6442^{*}$ & 1.82 & $(0.068)$ & 5.1771 \\
\hline supplementary ins. & 0.1258 & 0.38 & $(0.702)$ & 1.1341 \\
\hline private insurance & -0.0167 & -0.04 & $(0.965)$ & 0.9834 \\
\hline health status & $-0.2670^{* * *}$ & -3.66 & $(0.000)$ & 0.7657 \\
\hline age started smoking & -0.0398 & -1.35 & $(0.176)$ & 0.9610 \\
\hline constant & $-4.4803^{* *}$ & -2.29 & $(0.022)$ & \\
\hline d96 & 0.1781 & 0.67 & $(0.504)$ & \\
\hline d97 & 0.5295 & 1.57 & $(0.117)$ & \\
\hline d98 & $1.2544^{* * *}$ & 2.83 & $(0.005)$ & \\
\hline d99 & $1.4853^{* * *}$ & 2.66 & $(0.008)$ & \\
\hline $\mathrm{d} 00$ & $2.2891^{* * *}$ & 3.22 & $(0.001)$ & \\
\hline $\mathrm{d} 01$ & $3.2825^{* * *}$ & 3.41 & $(0.001)$ & \\
\hline
\end{tabular}


Table 3 continued

\begin{tabular}{lcccc}
\hline Hazard & coefficient & $\mathrm{Z}$ & $\mathrm{P}>|\mathrm{z}|$ & hazard $\mathrm{r}$. \\
\hline $\mathrm{d} 02$ & $2.6485^{* *}$ & 2.39 & $(0.017)$ & \\
Gamma var. & $15.2811^{* * *}$ & 2.64 & $(0.000)$ & \\
\hline LR test $\left(\chi^{2}\right)$ & $17.1346^{* * *}$ & & $(0.000)$ & \\
N & 15726 & & & \\
AIC & 3707.94 & & & \\
BIC & 3960.82 & & & \\
\hline
\end{tabular}

insurance. Several explanations can be found: First, our insurance dummies only capture the system in which the individual is insured or whether there exists supplemental insurance. In Germany, about 90 percent of the population are compulsorily insured in the Statutory Health Insurance (SHI) and only people with an earned income above the compulsory insurance income threshold are qualified to choose between social and private insurance. Moreover, people working as civil servants are partly privately insured. Therefore, insurance status incorporates also information about socioeconomic status, profession and the status and education of the parents.

Second, the monitoring and cost-sharing effects derived from the theoretical model cannot be separated precisely in our data. In contrast to social insurers, private health insurers and supplemental insurers use questionnaires before signing a contract but do not follow any further monitoring strategies. With respect to the cost-sharing effect, our results reflect the broad coverage in all kinds of health insurance systems. For the SHI insured individuals there is no variation in the insurance contract, apart from few exceptions. Benefits catalogue and copayments are largely regulated by the government. A clear trend only exists for supplemental insurance that goes along with a broader coverage than SHI and therefore reduced cost sharing. Hence, SHI-insured individuals with supplementary health insurance face less monetary risks when demanding health care. For fully private health insurance, the situation is more difficult to assess. Policyholders have the opportunity to choose between different levels of coverage and different forms of cost sharing. Third, the insurance result may be driven by our prevention variable "quit smoking" that covers only one single aspect of the multidimensional factor "preventive activities".

Considering the education effects, three ISCED dummies are significantly positive, namely upper secondary education as well as first and second stage of 
tertiary education. Hence, individuals with higher education or qualification tend to stop smoking more often, a result comparable to the findings in Mullahy (1997), Kenkel et al. (2006) or Cowell (2006). All other educational variables show no difference to the reference group (no completed education or first stage of basic education). If we interpret this as a better capability to process the available information in the sense of MAURER (2009) or VICK and SCOtT (1998), this confirms our second hypothesis that information is one key for enhancing prevention activities. The household income does not show a significant effect, but the influence of the variable economic worries is strongly negative. Worries about the future economic situation can then be interpreted as a proxy for socioeconomic status, leading to the conclusion that people with strong worries and therefore low status tend to quit smoking less often than others do. Concerning the working time, we observe a non-linear effect. First, increases in working time decrease the probability of stopping smoking. This may be due to work related burdens and stress. Second, with a further increase, the magnitude of this effect decreases.

Our measure of the health capital stock shows a significantly negative sign resulting in a lower probability of quitting. Therefore, one can conclude that people in a good health status and with fewer experiences concerning e.g. respiratory diseases caused by smoking do not feel the pressure to change their preventive behaviour. One interpretation might be that those individuals do not face the need to be informed about health risks related to their behaviour (cf. Kenkel, 1991). At first, this result seems counter-intuitive. But individuals with a higher health capital stock experience diminishing returns on additional prevention efforts. Therefore, their incentive to invest in future health might be lower compared to that of persons with a low health capital stock that face a health shock. This view neglects the result of the Grossman model that individuals with a high health capital stock invest more because of the higher opportunity costs of a health shock (Grossman, 1972).

The time dummies show a significant effect for all years after 1998. This implies a non-monotonic increase of the baseline hazard. In detail, we observe an increasing effect over time except for the year 2002. From 1995 to 2002 cigarette prices in Germany increased from 12.38 to 14.80 cent/cigarette (cf. van DeuVERDEN, 2004, p. 12). At the same time, tobacco taxes grew from 6.96 to 8.62 cent/cigarette. ${ }^{22}$ Therefore, one can conclude that the observed coefficients of the

22 We tested for a specification that includes cigarette prices or taxes as well. For every year, there is no variation between the individuals in our sample for both variables, which leads to collinearity problems. 
baseline hazard primarily show the effect of taxes and price increases. Finally, a likelihood ratio test is performed to check whether a model including individual heterogeneity using a gamma mixture distribution fits better than the standard Bernoulli distribution. Here, the hypothesis that there exists no difference between the two models can be rejected at the 1 percent level of significance. In other words, there exists a difference between the two specifications, namely a model using a gamma distribution for incorporating unobserved heterogeneity and the standard Bernoulli distribution. Together with the highly significant coefficient of the Gamma variance, we can conclude that unobservable heterogeneity between individuals is significant in the dataset and that this model specification is suitable (cf. Jenkins, 1997).

\section{Conclusion}

Using a principal-agent setting between insurer and patient, the paper at hand analyses the prevention decision with respect to different insurance settings. Our analysis describes the trade-off between the disutility of prevention activities and the reduced probability of illness. In detail, the effects of an insurance contract on preventive behaviour work through the cost sharing the patient has to bear and the monitoring activities that the insurer performs. We find that costsharing and monitoring effects crucially depend on the information transmitted between patient and insurer. Moreover, income-related contributions, which are not related to expected treatment costs, go along with lower incentives for prevention. In the analysis at hand, we assumed the patient's ability to control his prevention activities fully.

Our empirical specification tests the findings regarding cost sharing and information environment using German micro data. Applying a discrete-time proportional hazards model to the question of quitting smoking as a proxy for preventive behaviour, we find evidence that health capital stock and information play a central role in the decision about prevention. For the data at hand, an effect with respect to insurance coverage only exists for those individuals without health insurance. These individuals show a better behaviour than those with SHI coverage. Other effects for different insurance systems remain unclear for two reasons: First, health insurance serves as a kind of proxy for socioeconomic status and second, we do not find much variation in the data because information on co-payments and coverage is missing.

For health policy makers two points are worth mentioning. First, considering the coverage of health insurance systems and especially social health insurance, 
treatment strategies seem to be preferred to strengthen prevention. If legislators seek to enhance prevention, they should not narrow the focus to medical treatment, but should also set incentives for prevention. Nevertheless, one has to keep in mind that it is difficult to enforce prevention strategies if people do not react to premium or coverage changes. Second, the transmission of information plays a central role for the incentives to work; health policy should aim at strengthening the information exchange between patient, insurer and provider. This information exchange may fit better if organisational schemes like managed care are introduced that include guidelines not only for providers but also for patients.

\section{Appendix}

\section{a) Cost-Sharing-Effect}

\section{i. Risk-Orientated-Premiums}

Differentiation of equation (10) relating to the coverage $x$ gives the following result:

$$
\begin{aligned}
\begin{aligned}
\frac{d \hat{e}}{d x}= & -\frac{p^{\prime}(e) U_{S}^{\prime}[\lambda(e, m) \cdot(1-p(e))]+p^{\prime}(e) U_{H}^{\prime}[p(e) \cdot \lambda(e, m)]}{\Omega} \\
+ & \frac{p(e) U_{s}^{\prime \prime}[\lambda(e, m) \cdot(1-p(e))] \cdot \frac{\partial \lambda}{\partial e} x+p(e) U_{S}^{\prime} \frac{\partial \lambda}{\partial e}}{\Omega}
\end{aligned} \\
\text { with } \Omega=p^{\prime \prime}(e)\left(U_{S}-U_{H}\right)-\frac{\partial^{2} C(e)}{\partial e^{2}}+2 p^{\prime}(e) U_{S}^{\prime} \frac{\partial \lambda}{\partial e} x \\
\quad+p(e) U_{S}^{\prime \prime}\left(\frac{\partial \lambda}{\partial e} x\right)^{2}+p(e) U_{S}^{\prime}\left(\frac{\partial^{2} \lambda}{\partial e^{2}} x\right)<0, \text { if } \lambda(e) \text { is concave. }
\end{aligned}
$$

The denominator is a sufficient condition for a utility maximum and negative if $\lambda(e, m)$ is strictly concave. For the numerator the signature depends on the level of $\lambda(e, m)$. Allowing hypothetically for $\lambda \rightarrow 0$, the reduced fraction can be depicted as follows: 


$$
\begin{aligned}
\frac{d \hat{e}}{d x}= & -\frac{p^{\prime}(e) U_{S}^{\prime}[\lambda(e, m) \cdot \overrightarrow{0}(1-p(e))]+p^{\prime}(e) U_{H}^{\prime}(p(e) \cdot \vec{\lambda}(e, m))}{\Omega_{\lambda \rightarrow 0}} \\
& +\frac{p(e) U_{S}^{\prime \prime}[\lambda(e, m) \cdot \overrightarrow{0}(1-p(e))] \cdot \frac{\partial \lambda}{\partial e} x+p(e) U_{s}^{\prime} \frac{\partial \lambda}{\partial e}}{\Omega_{\lambda \rightarrow 0}} .
\end{aligned}
$$

The first, second and the third addend almost vanish due to the proximity of $\lambda$ to zero. Hence only the fourth addend will be relevant. Considering the concavity of $\lambda$ the marginal gain of an increase of $e$ is positive and the whole numerator gets positive. In consequence, $d \hat{e} / d x>0$ is possible for small values of $\lambda$.

For $\lambda>0$, the impact of $x$ on $e$ depends on the sign of the numerator. The first three terms are negative by definition and the fourth one is positive. For a value of $\lambda$ close to one, the first three terms become more negative, while the fourth one gets smaller. The latter effect results because the derivation of $\lambda$ with respect to $e$ gets smaller with $\lambda$ approaching one. To sum up, with a better information transmission, the impact of a better coverage on prevention becomes negative. If the coverage $x$ is higher the patient has a higher incentive to compare the opportunity costs of a higher coverage with the opportunity cost of bearing a higher cost-sharing component.

\section{ii. Income-Orientated Contributions}

Considering all insurers have to charge income-related contributions (compare equations (17) and (18)), the marginal effect of altering the level of coverage is:

$$
\begin{aligned}
& \frac{d \hat{e}}{d x} \mid \pi_{s}=-\frac{p^{\prime}(e) \cdot U_{S}^{\prime}\left[-\frac{\partial \pi_{s}}{\partial x}+\lambda(e, m)\right]-p^{\prime}(e) \cdot U_{H}^{\prime}\left[-\frac{\partial \pi_{s}}{\partial x}\right]}{\Omega} \\
& +\frac{p(e) \cdot U_{s}^{\prime \prime}\left[-\frac{\partial \pi_{s}}{\partial x}+\lambda(e, m)\right] \cdot \frac{\partial \lambda}{\partial e} x+p(e) \cdot U_{s}^{\prime} \frac{\partial \lambda}{\partial e}}{\Omega}
\end{aligned}
$$

Here, the 'premium-effect' is

$$
\frac{\partial \pi_{s}}{\partial x}=\frac{\partial \tau}{\partial x} \cdot W_{i}=\frac{(\alpha+\beta) \cdot p(e) \cdot \lambda(e, m)}{\alpha W_{\alpha}+\beta W_{\beta}} W_{i}
$$


Lemma 1: For all levels of $x \frac{\partial \pi_{s}}{\partial x}<\frac{\partial \pi}{\partial x}$ holds.

Proof:

If $\frac{\partial \pi}{\partial x}-\frac{\partial \pi_{s}}{\partial x}>0=p(e) \cdot \lambda \cdot\left(1-\frac{(\alpha+\beta) \cdot W_{i}}{\alpha W_{\alpha}+\beta W_{\beta}}\right)>0$, Lemma 1 holds.

Considering $W_{i}<W_{\alpha}+W_{\beta}$ is always true per assumption, the Lemma will be also true as long as $p(e)_{\alpha}=p(e)_{\beta}$ and $\lambda(e, m)_{\alpha}=\lambda(e, m)_{\beta}$.

By applying to Lemma 1, the marginal effect in the numerator of (A3) will exceed the numerator in the risk-orientated case. For $\lambda \rightarrow 0$, the numerator in (A3) gets positive. Compared to risk-orientated premiums, the effect of an increasing coverage on the prevention level is smaller due to the concavity of the utility function. For $\lambda \rightarrow 1$, $d \hat{e} /\left.d x\right|_{\pi_{S}}$ will be more negative than $d \hat{e} / d x$ because of diminishing premium effects upon the patient's prevention activities.

\section{b) Monitoring Effect}

\section{i. Risk-Orientated-Premiums}

Totally differentiating equation (8) with respect to monitoring efforts gives:

$$
\begin{aligned}
\frac{d \hat{e}}{d m}= & -\frac{p^{\prime}(e) U_{S}^{\prime}\left[(1-p(e)) \frac{\partial \lambda}{\partial m} x-1\right]-p^{\prime}(e) U_{H}^{\prime}\left[-p(e) x \frac{\partial \lambda}{\partial m}-1\right]}{\Omega} \\
& +\frac{p(e) U_{s}^{\prime \prime}\left[(1-p(e)) \frac{\partial \lambda}{\partial m} x-1\right] \frac{\partial \lambda}{\partial e} x+p(e) U_{s}^{\prime} \frac{\partial^{2} \lambda}{\partial e \partial m} x}{\Omega}
\end{aligned}
$$

The sign of the effect of $m$ on $e$ depends on three different effects. First, a higher level of monitoring goes along with a better treatment received because of the positive marginal productivity of $m$ on $\lambda(\partial \lambda / \partial m) x$. Second, the premium changes with respect to $m$ depend on the trade-off between better information and higher costs of $m:(p(e)(\partial \lambda / \partial m) x-1)$. Third, there exists a strategic dependence between $e$ and $m$ in the information transmission $\left(\partial^{2} \lambda / \partial e \partial m\right)$.

For small values of $m$, the effect of a better treatment dominates the premium changes and the term in square brackets of addend one and three is positive. The 
single premium effect in the second addend is negative. As long as we observe the case of strategic substitutes, the numerator gets negative and the overall result of a better monitoring on prevention is negative $(d \hat{e} / d m<0)$.

For a positive effect, it is necessary that the strategic interaction is positive (strategic complements). Moreover, since the second addend is always negative, the first and the third addend have to be positive given that the expression in square brackets is negative. This means that the negative premium effect of enhanced monitoring outweighs the positive treatment effects from the patient's point of view and therefore results in a loss of income.

\section{ii. Income-Orientated Contributions}

For discussing the case of income-orientated contributions, the marginal effect has to consider the new premium effect:

$$
\begin{gathered}
\frac{\partial \pi_{s}}{\partial m}=\frac{\partial \tau}{\partial m} \cdot W_{i}=\frac{(\alpha+\beta) \cdot\left(p(e) \cdot \frac{\partial \lambda}{\partial m} \cdot x+1\right)}{\alpha W_{\alpha}+\beta W_{\beta}} W_{i} \\
\frac{d \hat{e}}{d m} \mid \pi_{s}=-\frac{p^{\prime}(e) \cdot U_{s}^{\prime}\left[-\frac{\partial \pi_{s}}{\partial m}+\frac{\partial \lambda}{\partial m} x\right]-p^{\prime}(e) \cdot U_{H}^{\prime}\left[-\frac{\partial \pi_{s}}{\partial m}\right]}{\Omega} \\
+\frac{p(e) \cdot U_{s}^{\prime \prime}\left[-\frac{\partial \pi_{s}}{\partial m}+\frac{\partial \lambda}{\partial m} x\right] \frac{\partial \lambda}{\partial e} x+p(e) \cdot U_{s}^{\prime} \frac{\partial^{2} \lambda}{\partial e \partial m} x}{\Omega} x
\end{gathered}
$$

Lemma 2: For all levels of $\mathrm{m} \partial \pi_{s} / \partial m<\partial \pi / \partial m$ holds.

Proof: Similar to Lemma 1, Lemma 2 holds as long as $W_{i}<W_{\alpha}+W_{\beta}$ and $p(e)_{\alpha}=p(e)_{\beta}$ and $\lambda(e, m)_{\alpha}=\lambda(e, m)_{\beta}$.

By applying to Lemma 2, the marginal effect of the numerator in (A5) will exceed the numerator in the risk-orientated case. In consequence, $d \hat{e} /\left.d m\right|_{\pi S}$ will be more negative than $d \hat{e} / d m$ as long as $\left(\partial^{2} \lambda / \partial e \partial m\right) x<0$ is valid. Only if monitoring works as a kind of strategic complement $\left(\left(\partial^{2} \lambda / \partial e \partial m\right) x>0\right)$ there is the possibility of increasing prevention activities by additional monitoring efforts. 


\section{References}

Barigozzi, Francesca (2004), "Reimbursing Preventive Care", The Geneva Papers on Risk and Insurance Theory, 29, pp. 165-186.

Becker, Gary, and Kevin Murphy (1988), "A Theory of Rational Addiction", Journal of Political Economy, 26, pp. 675-700.

Chaloupka, Frank, and Kenneth Warner (1999), "The Economics of Smoking”, NBER Working Paper W7047, Cambridge/Mass.

Cohen, Alma, and Litan Einav (2007), "Estimating Risk Preferences from Deductible Choice", American Economic Review, 97, pp.745-788.

Cohen, Joshua, Peter Neumann, and Milton Weinstein (2008), "Does Preventive Care Save Money? Health Economics and the Presidential Candidates", New England Journal of Medicine, 358, pp. 661-663.

Contoyannis, Paul, and Andrew M. Jones (2004), "Socio-Economic Status, Health and Lifestyle", Journal of Health Economics, 23, pp. 965-995.

Cowell, Alexander J. (2006), "The Relationship between Education and Health Behavior: Some Empirical Evidence", Health Economics, 15, pp. 125-146.

Disney, Richard, Carl Emmerson, and Matthew Wakefield (2006), "Ill Health and Retirement in Britain: A Panel Data-based Analysis", Journal of Health Economics, 25, pp. 621-649.

Dracup, Kathleen A., and Afaf J. Meleis (1982), "Compliance: an Interactionist Approach", Nursing Research, 31, pp. 31-36.

Ehrlich, IsaAC, and Gary Becker (1972), "Market Insurance, Self-Insurance, and Self-Protection", The Journal of Political Economy, 80, pp. 623-648.

Ellis, Randell P., and Willard G. Manning (2007), "Optimal Health Insurance for Prevention and Treatment", Journal of Health Economics, 26, pp. 1128-1150.

Forster, Martin, and Andrew M. Jones (2001), "The Role of Tobacco Taxes in Starting and Quitting Smoking", Journal of the Royal Statistical Society, Series A, Statistics in Society, 164, pp. 517-547.

Giveon, Shmuel, and Ernesto Kahan (2000), "Patient Adherence to Family Practitioners' Recommendations for Breast Cancer Screening: A Historical Cohort Study", Family Practice, 17, pp. 42-45.

Greenlund, Kurt, Notal Keenan, Lynda Anderson, Margaret Mandelson, Catharine Newton, and Andrea LaCroix (2000): "Does Provider Prevention Orientation Influence Female Patients' Practices?”, American Journal of Preventive Medicine, 19, pp. 104-110.

Grossman, Michael (1972), "On the Concept of Health Capital and the Demand for Health", Journal of Political Economy, 80, pp.223-255. 
Hagan, Ronald, Andrew M. Jones, and Nigel Rice (2006), "Health and Retirement in Europe", HEDG Working Paper 06/10, University of York.

Haynes, R. Brian (1978), "Introduction", in: R. Brian Haynes, David Sackett, and Wayne Taylor (eds), Compliance in Health Care, Johns Hopkins Press, Baltimore, pp. 1-18.

Haynes R. Brian, Heather McDonald, Amit Garg, and Paul Montague (2002), "Interventions for Helping Patients to Follow Prescriptions for Medications", The Cochrane Database of Systematic Reviews, Issue 2.

Hernández-Quevedo, Cristina, Andrew M. Jones, and Nigel Rice (2005), "Reporting Bias and Heterogeneity in Self-assessed Health. Evidence from the British Household Panel Survey", HEDG Working Paper 05/04, University of York.

Jenkins, Stephen P. (1995), "Easy Estimation Methods for Discrete-Time Duration Models", Oxford Bulletin of Economics and Statistics, 57, pp. 129-138.

Jenkins, Stephen P. (1997), "Discrete Time Proportional Hazards Regression", The Stata Technical Bulletin Reprints, 7, pp. 109-121.

Jones, Andrew M. (2007), "Panel Data Methods and Applications to Health Economics”, HEDG Working Paper 07/18, University of York.

Kenkel, Donald S. (1991), "Health Behavior, Health Knowledge, and Schooling", The Journal of Political Economy, 99, pp. 287-305.

Kenkel, Donald S. (2000) "Prevention", in: Anthony J. Culyer und Joseph P. Newhouse (eds), Handbook of Health Economics Volume 1B, Amsterdam et al., pp. $1675-1720$.

Kenkel, Donald S., Dean Lillard, and Alan Mathios (2006), "The Roles of High School Completion and GED Receipt in Smoking and Obesity", Journal of Labor Economics, 24, pp. 635-660.

Macho-Stadler, Ines, and J. David Pérez-Castrillo (2001), An Introduction to the Economics of Information: Incentives and Contracts, 2nd edition, Oxford.

Mas-Colell, Andrew, Michael Whinston, and Jerry Green (1995), Microeconomic Theory, Oxford.

Maurer, Jürgen (2009), "Who Has a Clue to Prevention the Flu? Unravelling Supply and Demand Effects on the Take-Up of Influenza Vaccinations", Journal of Health Economics, 28, pp.704-717.

Miceli, Thomas J., and Dennis Heffley (2002), "Do HMOs Encourage Prevention?: An Analysis of Alternative Health Care Plans", Contemporary Economic Policy, 20, pp.429-439. 
Mullahy, John (1997), "Instrumental-Variable Estimation of Count Data Models: Applications to Models of Cigarette Smoking Behavior", Review of Economics and Statistics, 79, pp. 586-593.

Neubauer, Simone, Robert Welte, Alexandra Beiche, Hans-Helmut Koenig, Katharina Buesch, and Reiner Leidl (2006), "Mortality, Morbidity and Costs Attributable to Smoking in Germany: Update and a 10-Year Comparison", Tobacco Control, 15, pp.464-471.

Poutvaara, Panu, and Lars H. Siemers (2008), "Smoking and Social Interaction", Journal of Health Economics, 27, pp. 1503-1515.

Rice, Dorothy, Thomas Hodgson, Peter Sinsheimer, Warren Browner, and Andrea Kopstein (1984), "The Economic Costs of the Health Effects of Smoking", The Milbank Quarterly, 64, pp. 489-547.

Schauffler, Helen H., and Michael D. Parkinsion (1993), "Health Insurance Coverage for Smoking Cessation Services", Health Education Quarterly, 20, pp. 185-206.

Shavell, Steven (1979), "On Moral Hazard and Insurance”, Quarterly Journal of Economics, 93, pp. 541-562.

STEWART, JARY (1994), "The Welfare Implications of Moral Hazard and Adverse Selection in Competitive Insurance Markets", Economic Inquiry, 32, pp. 193-208.

Sturm, Roland (2002), "The Effects of Obesity, Smoking, and Drinking on Medical Problems and Costs", Health Affairs, 21, pp. 245-253.

van Deuverden, Kristina (2004), „Die Erhöhung der Tabaksteuer zur Finanzierung versicherungsfremder Leistungen in der gesetzlichen Krankenversicherung" (The Increase of Tobacco Taxes to Finance Extraneous Insurance Benefits in the German SHI), Discussion Paper 187, Halle Institute for Economic Research.

Vick, Sandra, and Anthony Scott (1998), "Agency in Health Care. Examining Patients' Preferences for Attributes of the Doctor-Patient Relationship", Journal of Health Economics, 17, pp. 587-605.

Volpp, Kevin, Andrea Troxel, Marc Pauly, Henry Glick, Andrea Puig, David Asch, Robert Galvin, Jingsan Zhu, Fei Wan, Jill DeGuzman, Elizabeth Corbett, Janet Weiner, and Janet Audrain-McGovern (2009), "A Randomized, Controlled Trial of Financial Incentives for Smoking Cessation”, New England Journal of Medicine, 360, pp. 699-709.

Welte, Robert, Hans-Helmut König, and Reiner Leidl (2000), “The Costs of Health Damage and Productivity Losses Attributable to Cigarette Smoking in Germany", European Journal of Public Health, 10, pp.31-38. 
Wooldridge, Jefreey M. (2002), Econometric Analysis of Cross Section and Panel Data, Cambridge et al.

Zweifel, Peter, and Willard G. Manning (2000), "Moral Hazard and Consumer Incentives in Health Care", in: Anthony J. Culyer and Joseph P. Newhouse (eds), Handbook of Health Economics, Vol. 1A, Amsterdam et al., pp. 409-459.

\section{SUMMARY}

This paper explores the effects of insurance parameters and complementary information environment on the patient's primary prevention activity. The theoretical model is based on a principal-agent setting in which the patient acts as an agent in deciding about his prevention efforts. The insurer chooses the coverage level and therefore the level of patient's cost sharing and decides on his monitoring activities. The empirical analysis looks at the patient's prevention decision in the case of smoking. Using a hazard model in discrete time, the decision to change behaviour depends on health status, education, age and working time but not on the insurance system. 